\title{
Multiple Output Analysis for Advanced Waveform and Controlled Short-circuit MIG/MAG Variants
}

\section{Régis Henrique Gonçalves e Silva}

Welding and Mechatronics Institute, LABSOLDA, Federal University of Santa Catarina, Florianópolis-SC, Brazil

Daniel Galeazzi ( $\boldsymbol{D}$ daniel.galeazzi@posgrad.ufsc.br)

Federal University of Santa Catarina: Universidade Federal de Santa Catarina

\section{Pedro Correa Jaeger Rocha}

Welding and Mechatronics Institute, LABSOLDA, Federal University of Santa Catarina, Florianópolis-SC, Brazil

\section{Alberto Bonamigo Viviani}

Welding and Mechatronics Institute, LABSOLDA, Federal University of Santa Catarina, Florianópolis-SC, Brazil

\section{Rafael Albino Bernardi}

Welding and Mechatronics Institute, LABSOLDA, Federal University of Santa Catarina, Florianópolis-SC, Brazil

\section{Research Article}

Keywords: GMAW, Modified arc, derivative process, metal transfer, short arc

Posted Date: April 14th, 2021

DOl: https://doi.org/10.21203/rs.3.rs-404672/v1

License: (c) (1) This work is licensed under a Creative Commons Attribution 4.0 International License.

Read Full License

Version of Record: A version of this preprint was published at Welding in the World on September 15th, 2021. See the published version at https://doi.org/10.1007/s40194-021-01176-2. 


\section{Abstract}

The latest advancements of MIG/MAG welding technologies have experienced a steep evolution in functionality, reliability and ever-growing process and weld controllability, within widely interdisciplinary approaches and driven by demanding trends of Advanced Manufacturing (Industry 4.0). Technologic development can be optimized through basic research, which focuses on understanding the physical phenomena involved in metal transfer, weld pool behavior and bead geometric formation and their correlation with each other and with the process's variables. In this context, the objective of this work is to compare different waveforms of the short-circuiting MIG / MAG process with current control, namely CCC and SOFT, with the conventional process version, evaluating the influence of the electrical parameters on process stability and the general morphology of the weld beads. Analysis of metal transfer by means of high-speed filming and thermal analysis by infrared thermography supported conventional oscillogaphic monitoring for process characterization. Spatter emission assessment by means of image analysis was performed as well. The process's versions with current control resulted in better operational weldability, geometric control of the bead and lower spatter emission.

\section{Introduction}

The MIG/MAG process as we know it originated circa 1920, however, due to the scarcity of technological resources and research in this area, the economic and commercial viability of this process was limited until the 1940s. With the impulse of the Second World War, the process began to be researched with emphasis, originally patented in the USA, in 1949, for welding aluminum in a protective helium atmosphere [1, 2].

The MIG/MAG process's greatest impact characteristic is the productivity that can be achieved as a result of its semi-automatic nature and high current density, resulting in high deposition rates and high work factor, flexibility and automatability, while maintaining the required quality in several applications [3]. The MIG/MAG process, depending on the material and current intensity, can operate in different metal transfer modes, basically short-circuiting, globular and spray [2]. Each mode has different dynamic characteristics as well as applications. In this work, the metal transfer mode analyzed was exclusively the shortcircuiting one.

In conventional short-circuiting voltage is controlled, i.e., power sources of the constant voltage type are used and the operator adjustable variables are voltage and wire feed speed. The resulting current intensity will be a consequence of the conjunction of these two.

Each conventional short-circuiting metal transfer event starts with the contact between the wire electrode's molten tip (droplet) and the molten pool, thus forming a liquid metallic bridge. The electric current abruptly rises and the conduction area decreases (constriction of the metallic bridge). The Pinch Effect grows exponentially, because it is are proportional to the square of the current and its density. From the rupture of the metal bridge, the arc restrikes and is established again. At this moment, the current is at 
a high level and the voltage overthoots, exceeding the adjusted value. The power source imposes the adjusted voltage, also causing a reduction in the current. When the arc voltage reaches the regulated value, the arc current stabilizes. The current, during the arc, causes the formation of a new metallic drop and keeps the weld pool at a high temperature. In order to illustrate the behavior of the short-circuiting MIG/MAG process, Fig. 1 shows its typical waveform.

Both current increase and decrease dynamics are a function of the constructively defined internal inductance of the welding power source, deprived of any means to adjust / parameterize the inductance value and, so, optimize the current dynamic behavior. The rupture of the metal bridge and detachment of a drop always occur at high currents and high voltages, hence high power, and this generates an explosive effect on the molten pool that expels spatter, aside from generating metal transfer and oscillographic instabilities on the process. However, many advances have been made, e.g., by means of inductance control of the process and also with the advancement of power electronics and current waveform control, which can be designed to offer the best operational performance, consuming less energy with greater efficiency.

Numerous studies have been conducted to improve metal transfer methods using the MIG/MAG process with a main focus on the industry, aiming to reduce costs, eliminate waste and increase productivity. In this context, process variants have been developed that make it possible to control the metal transfer event and average thermal input, by controlling the current waveform [4]. Within this array, the CCC version (Controlled short-circuit) of the Brazilian supplier IMC, and the American STT (Surface Tension Transfer) from Lincoln Eletric and RMD (Regulated Metal Deposition) from Miller Electric can be mentioned, within a wide spectrum of versions with different technical peculiarities and brand names [5].

Kah et al. [5] presents a review of the developments regarding the processes with consumable electrode (MIG/MAG), particularly the effect of parameterization and construction of the current waveform. The study shows that, using controlled short-circuit for welding thin sheets, it is possible to obtain good weldability, good mechanical properties of the joint and increased productivity. These results corroborate with Mvola et al. [6], who developed a study to identify the impact of different waveforms on the metal transfer of the MIG/MAG process aiming at the improvement of the metal and heat transfer conditions of the electrode to the base metals. The analysis shows that the controlled short circuit can present higher thermal efficiency aside from a significant effect on the control of the heat input and reduction of the generation of spatter and fumes. However, the low heat input effect of these processes may impair or make it unfeasible to use in certain applications.

The spatter and fumes generation are an inherent characteristic of the conventional short-circuiting MIG/MAG process, due to the breaking of the metal bridge at a high electric power level. Studies show that the conjunction of parameters such as arc length, arc time and drop diameter can increase the spatter and fumes generation, as well as operational instability [7]. Spatter and fumes reduction consists in one of the waveform control main goals. The aim of the control routine is to very quickly detect the droplet-pool contact and the imminence of detachment of the metal droplet, and react adequately to each 
event. Some of the marketed process variants do not predict and react in anticipation of arc restriking, as SOFT and coldMIG, and are designated as "semi-controlled short-circuiting" process. Dutra and Silva [8] present a study using the CCC variant of the short-circuiting MIG/MAG process, whose results indicate a significant reduction of spatter, Fig. 2.

The statistical analysis of the welding processes oscillograms can provide information about the metal transfer and many analysis methods have been created to quantify stability. These methods relate voltage and current, as well as their continuity over time $[9,10,11]$. Nevertheless, different methods can be employed, such as image or video analysis, using segmentation for identification and cycle counting through the spatter emission $[12,13]$. Process sound analysis is also a valid method to evaluate stability $[14,15]$. However, most methods are based on the relative standard deviation, that is, the ratio between the standard deviation and the mean value of a sample; the closer to 1, the greater the stability. Buki and Gorenshtein [9], Shinoda et al. [10] and Kuszelyko [11] present as stable processes with a stability coefficient (relative standard deviation) greater than 0.65, described in Eq. (1), where $\sigma$ represents the standard deviation and $\mu$ represents the average.

$$
\varepsilon=1-\frac{\sigma}{\mu}
$$

The objective of the present work is to compare different short-circuiting MIG/MAG waveforms with current control, using the same wire feed speed and average current, evaluating the influence of electrical parameters on the stability and general morphology of the weld beads. For this purpose, oscillographic analysis of voltage, current and power were used. Analysis of metal transfer by means of high-speed videography and monitoring of base metal thermal profiles, by means of infrared thermography, were applied. A method for evaluation of spatter emission through image analysis and its validation belonged to the stated goals as well.

\section{Experimental Procedure}

AISI 1020 carbon steel plate with $9.52 \mathrm{~mm}$ thick, $100 \mathrm{~mm}$ wide and $250 \mathrm{~mm}$ long were applied as base metal. The bead-on-plate welds were performed along $200 \mathrm{~mm}$ in the plate center, using ER70S6 steel wire of $1.2 \mathrm{~mm}$ in diameter. The gas mixture with 25\% CO2 and 75\% Argon was used as shielding gas, with a $12 \mathrm{~L} / \mathrm{min}$ flow. The processes to be compared were the conventional short-circuiting MIG/MAG (voltage source - CV) and two current controlled (CC) versions, namely the CCC (controlled short-circuit) and the SOFT (semi-controlled short-circuit). For all experiments, the wire feed speed was $3.0 \mathrm{~m} / \mathrm{min}$ and welding speed, $25 \mathrm{~cm} / \mathrm{min}$. The starting base metal temperature for all weld beads was room temperature.

The voltage and current signals were simultaneously measured during welding by means of a system with four acquisition channels and $5 \mathrm{kHz}$ acquisition frequency (SAP). The voltage signal was measured between the workpiece and welding torch and the current signal through a coaxial Hall effect sensor 
around the ground cable. These signals were used to analyze the effect of the waveform on stability, molten pool dynamics and temperature (heat input and heat transfer).

In order to identify the phenomena involved in metal transfer in more detail, the IDT Motion Pro Y4-S2 camera was used for high speed filming, with an acquisition rate of 5000 frames per second. The camera was positioned at $10^{\circ}$ to the plate surface. A LASER CAVILUX HF lighting system with $800 \mathrm{~nm}$ and $500 \mathrm{~W}$ power was used to mitigate the light emitted by the arc.

The acquisition of the thermal profile generated by each variant of the MIG/MAG process was made with a FLIR SC7000 thermographic camera, with an acquisition rate of $25 \mathrm{~Hz}$ and a resolution of $320 \times 256$, where each pixel is equivalent to $29 \mu \mathrm{m}$. The temperature range of 300 to $1500^{\circ} \mathrm{C}$ with an emissivity of 0.7 was used. Footage was performed on the back of the plate to attenuate the influence of the arc on the reading. The camera was positioned at $90^{\circ}$ to the surface of the plate $1.0 \mathrm{~m}$ away from it. Figure 3 illustrates the experimental setup scheme.

To assess the temperature profiles for each process, measurements along the transversal and longitudinal section of the ROI (region of interest) at the weld bead central region were performed when the process reached permanent regime. Temperature variation over time was also observed. For this analysis, the camera's dedicated software, Altair 5.9, was used. Figure 4 illustrates the measurement scheme adopted.

An image analysis technique was conceived, developed and used to evaluate, compare and quantify the waveform effect at the spatter emission of the MIG/MAG processes variants. The method consisted in filming the weld deposition with an opaque shield in front of the arc region and, by means of image analysis (thresholding, segmentation and binarization of an array of frames acquired during a set acquisition time), determining a spatter generation index represented by a qualitative percentage value. For this, a SONY DSC H300 camera with 720p resolution and $30 \mathrm{~Hz}$ acquisition rate was used. The image treatment algorithm was developed in MATLAB R2018a. Figure 5 schematically illustrates the method of determining spatter developed.

Subsequently, V-groove butt joint welds were performed with a $60^{\circ}$ opening angle, root opening of $2.5 \mathrm{~mm}$ and plate thickness of $12.5 \mathrm{~mm}$. The root and filling passes were geometrically evaluated t(total number of passes, considering the root pass, was four). Cross section macrographs were performed both in the plate and joint deposits and a $2 \%$ nital (nitric acid) submersion for three seconds was applied for etching.

\section{Results And Discussion}

Initially, each stage of the current waveforms was identified. As mentioned, the waveforms used are called CCC and SOFT. Their typical formats are described in Fig. 6. Each stage represents a parameter that can be adjusted, except short-circuit times, that depend on the power source's internal control algorithm. 
With reference to the above-mentioned waveforms and Fig. 6, Table 1 describes the function of each waveform stage on the process.

Table 1

- Process parameters open to operator adjustment, relative to Fig. 6.

\begin{tabular}{|lll|}
\hline \multicolumn{2}{|c|}{ CCC } & SOFT \\
\hline 1 & Base arc current & Base arc current \\
\hline 2 & $\begin{array}{l}\text { Current decrease to low value }(<40 \mathrm{~A}) \text { due the short- } \\
\text { circuit }\end{array}$ & $\begin{array}{l}\text { Current increase at constant rate after } \\
\text { pre-programmed delay due short- } \\
\text { circuit }\end{array}$ \\
\hline 3 & $\begin{array}{l}\text { Current pulse to increase the metallic bridge striction } \\
\text { rate }\end{array}$ & Arc current after droplet transfer \\
\hline 5 & $\begin{array}{l}\text { Constant current increase until the droplet transfer } \\
\text { eminence }\end{array}$ & $\begin{array}{l}\text { Current decrease at constant rate for } \\
\text { base arc current }\end{array}$ \\
\hline 6 & $\begin{array}{l}\text { Arc current pulse to wire fusion, new drop formation } \\
\text { and heat the weld pool }\end{array}$ & - \\
\hline 7 & $\begin{array}{l}\text { Constant arc current decrease for the weld pool } \\
\text { oscillation control }\end{array}$ & - \\
\hline 8 & $\begin{array}{l}\text { Arc current for the weld pool oscillation control } \\
9\end{array}$ & \begin{tabular}{l} 
Constant arc current decrease to base arc current \\
\hline
\end{tabular}
\end{tabular}

The tests resulted in an average current of $100 \mathrm{~A}$ for the conventional MIG/MAG and CCC processes and $114 \mathrm{~A}$ for the SOFT, considering the resolution of the hall sensor $(5,0 \mathrm{~A})$ this difference can be disregarded. For practical applications, this difference do not yield appreciable influence on the process nor on the weld. This similarity is expected mainly due to the wire feed speed being equal for all processes. The method of Buki and Gorenshtein [9], Shinoda et al. [10] and Kuszlyk [11] was used to measure stability, which is expressed by the ratio between the standard deviation of the welding cycles and the average of these. Processes are considered stable with a ratio of 0.6 and above (closer to 1 means greater stability). From the processes analyzed, 0.75 resulted for $\mathrm{CCC}, 0.65$ for SOFT and 0.6 for conventional Short-circuiting, that is, all processes showed good stability. However, in the SOFT process, considerable variations in the arc restriking current were observed (Fig. 7). Oscillation of the weld pool is believed to cause either premature short-circuits, or an extension of the arc time (time between shortcircuits), leading to larger droplets, which in turn take more time to be constricted and fully transferred to the molten pool, thus allowing the short-circuit current to increase for a longer time (longer short-circuit time). The voltage variation corroborates this hypothesis, as the process operates in controlled current mode (CC) and the variations in arc length directly influence the voltage. This hypothesis was tested via high speed filming, as discussed ahead. 
With regard to electric power, the conventional short-circuiting process consumed an average of $1.9 \mathrm{~kW}$, the SOFT, approximately $2 \mathrm{~kW}$ and the CCC, $1.8 \mathrm{~kW}$. These values are relatively similar, although the dynamic effect associated to the detachment is different, what can be observed by the instantaneous power values, at droplet detachment / liquid bridge rupture. The effect of arc re-ignition at high energy levels, is prominent with the conventional MIG/MAG and SOFT, whereby an explosive effect on the melt pool is observed, which expels material in the form of spatter, and contributes to the formation of fumes and metal vapors. The reignition power for the conventional process was $6 \mathrm{~kW}$. For the SOFT version, the re-ignition power was lower, $3.8 \mathrm{~kW}$, as a result of current control and advanced power source dynamics (electronically adjusted low inductance). In this technology, current is forced to decrease very rapidly (175 $\mathrm{A} / \mathrm{ms}$ ) to an intermediate level for a programmed period, in this case, $2 \mathrm{~ms}$. For CCC, the arc re-ignition power was about $1.8 \mathrm{~kW}$, significantly lower than the other versions. This performance derives from the waveform and control logic applied, which detects the imminence of liquid bridge rupture and acts in anticipation of the arc restriking event, forcing the current to rapidly decrease prior to effective restriking, The behavior of the instantaneous power for all three MIG/MAG variants can be seen in Fig. 8 .

Considering an analysis time window of $500 \mathrm{~ms}$. the area below the power graphic, representing the energy dispensed for each droplet detachment period (time between subsequent short-circuits, or time of waveform cycle), was calculated through integral methods. As a result, a value of $37.6 \mathrm{~J}$ was obtained for the conventional short-circuiting process, $37.4 \mathrm{~J}$ for the CCC process and $32.6 \mathrm{~J}$ for SOFT. Figure 9 illustrates the region of the graphic (droplet detachment period) adopted for the calculation. It can be seen that the conventional short-circuiting and the CCC showed similar values, both higher than SOFT.

However, SOFT imposes more energy per millisecond (average power) because the average periods are shorter, as previously discussed. Considering the arc time (apart from the short-circuit time), the average energy consumed per millisecond by the conventional version was $1.88 \mathrm{~J} / \mathrm{ms}$, for CCC $1.5 \mathrm{~J} / \mathrm{ms}$ and for SOFT $2.4 \mathrm{~J} / \mathrm{ms}$. This higher energy input was associated with a greater heating of the molten pool, effect that was visualized by thermal imaging.

In the conventional process, the current reduces after droplet detachment, and the reduction rate depends on the inductance of the system, which is inflexibly defined by constructive characteristics of the power source, down to the current that corresponds to the target voltage value. In the $\mathrm{CCC}$, after detachment, the current is kept at a low level ( $<40 \mathrm{~A})$ to avoid high power values at arc re-ignition, drastically reducing the spatter emission. After this period, which lasts about $1 \mathrm{~ms}$, a high-level current pulse is imposed, enough to melt the wire electrode and form another droplet. Current decreases, then, at a controlled rate, which is flexibly adjusted for each welding conditions for optimized results. With this, not only pool oscillation can be minimized, by decelerating the current drop and, thus, dampening the arc pressure over the weld pool, but also weld bead geometric features can be manipulated. In the SOFT process version, the current is reduced at high rate $(175 \mathrm{~A} / \mathrm{ms})$ from its peak and after detection of droplet detachment/arc restriking, to an intermediate (but still relatively high) level (between $100 \mathrm{~A}$ and $200 \mathrm{~A}$ ), aiming at the reduction of the spatter emission and consequent greater stability. The current control algorithm then keeps the current in 
this intermediate phase for a constant period, thus generating the needed energy input during the arc phase. A dampening effect of weld pool oscillation can also be seen through high-speed videography.

Arc phases' time histograms analysis show longer short-circuit times, about $2.3 \mathrm{~ms}$, and shorter open arc times are found for SOFT. This means smaller droplet transfer cycles and thus higher detachment rate, about $70 \mathrm{~Hz}$. Another peculiar effect verified was the bimodal distribution in the arc time histogram, which indicates that there are variations in the detachment period, which corroborates with the suggested hypothesis of melt pool oscillation for this process variant. Concerning the other processes, short-circuit time values of $1.8 \mathrm{~ms}$ for CCC and $2.3 \mathrm{~ms}$ for the conventional MIG/MAG were observed. Conventional MIG/MAG's and CCC's lower short-circuit times are due to higher current rise rates, $85 \mathrm{~A} / \mathrm{ms}$ and $90 \mathrm{~A} / \mathrm{ms}$ respectively, whereby SOFT's short-circuit current raise at a $50 \mathrm{~A} / \mathrm{ms}$ rate thus resulting in higher constriction rates of the liquid metal bridge. The arc time for the CCC presented the higher value, $18 \mathrm{~ms}$, as a function of the initial current pulse that increases arc pressure, pushes the weld pool down and keeps the arc length higher than the others keep. Consequently, the CCC presented the lowest detachment rate, about $50 \mathrm{~Hz}$. For the conventional version, the arc time was $16 \mathrm{~ms}$. The histograms of the processes are shown in Fig. 10.

Through high-speed filming, it was possible to verify the effect of the intensity of the arc current on the weld pool dynamic behavior, whereby a crater is formed as a function of the pressure exerted by the arc. Knowing the camera position in relation to the workpiece and using the orthogonal projection technique, it is possible to extract the crater dimensions. The crater formed by the conventional MIG/MAG process presented the larger dimensions; however, it is refilled faster than the others, within about $5.2 \mathrm{~ms}$, This effect occurs due to the faster current downslope, and consequently faster arc pressure downslope. The CCC presented the smallest crater and also the shallowest one, even with the high intensity current pulse. Its crater duration (time to refill of the crater with liquid metal) was also the shortest, about $3.0 \mathrm{~ms}$. In SOFT, the crater showed dimensional and duration similarity with the conventional short-circuiting MIG/MAG. This highlights the influence of the arc reignition power, higher for CCC and conventional MIG/MAG, over the crater, or depression. The effects of crater formation and size definition of the weld pool have influence over the wettability and penetration of the weld whereby temperature and arc pressure are, respectively, main actors. IR Thermographic imaging corroborate this statement, as addressed ahead. Figure 11 shows the high-speed frames that illustrate the formation and attenuation of the crater formed on the molten pool.

Further high-speed videography analysis was carried out in order to verify the afore described hypothesis of the arc time bimodal histographic behavior deriving from premature short-circuits. The footage showed that, occasionally, the oscillation amplitude increases and generates premature wire electrodemolten pool contacts. This effect can be seen in frame 4-5 of Fig. 12. However, even if this effect occurs in an unpredictable way, the current control of the process provides stability.

Thermal imaging was carried out to validate the hypothesis that, due to greater energy in the arc phase of the SOFT process, it generates the greatest thermal contribution on the molten pool. The results obtained 
corroborate the hypothesis, as can be seen in the thermograms of Fig. 13.

It is important to mention that the thermal frames in Fig. 13 were extracted when the thermal profile reached a permanent regime. SOFT presented a wider and hotter thermal profile with a maximum temperature of $\sim 600^{\circ} \mathrm{C}$. The CCC and the conventional short-circuiting MIG/MAG did not present a significant difference, whereby the latter presents a slightly larger area and temperature. Figure 14 illustrates the temperature values of the transversal and longitudinal sections (across the center of the hotter region) of the thermograms of Fig. 13.

Temperature variations over time at first seconds indicate that SOFT presents a higher heating rate than the others, also holding the average temperature of $600^{\circ} \mathrm{C}$, against $500^{\circ} \mathrm{C}$ for both CCC and conventional processes (Fig. 15). The superior heating effect presented by SOFT can be a correlation between its prevailing longer arc time histographic behavior and the higher power during the arc time.

Macrographs of the weld beads were performed to check if both the crater effect visualized in high-speed filming and the higher temperatures obtained by SOFT reflect in greater penetration, dilution and wettability. Figure 16 illustrates a comparison between the samples extracted from the center of the weld bead deposited.

The SOFT variant yielded a greater dilution than the others, a larger bead width with a shorter reinforcement. The conventional short-circuiting process, on the other hand, yielded the highest reinforcement and smallest width. Concerning the bead geometric dimensions, the CCC was somewhat intermediary, with the smallest HAZ (Heat affected zone) and a finger-shape penetration profile. Table 2 shows the dilution values, as well as widths and heights of the beads. It is interesting to point out that the bead is wider for CCC than for the conventional MIG/MAG, despite a smaller weld pool for the former.

Considering that the three processes variants have practically the same average current and power, it could be hypothesized that: - the smaller HAZ for CCC derives from its smaller weld pool crater and thus less heat transferred from the arc through the pool to the plate; - the wider and shorter SOFT bead derives from its higher arc time power; - the most convex shape of the conventional MIG/MAG shape derives from its lowest arc time power.

Table 2

- Analysis of the profile of macrographs

\begin{tabular}{|llll|}
\hline & Dilution (\%) & Width $(\mathrm{mm})$ & Heigth $(\mathrm{mm})$ \\
\hline Conventional & $24,4 \%$ & 5,96 & 2,51 \\
\hline CCC & $22,2 \%$ & 6,35 & 2,50 \\
\hline SOFT & $27,5 \%$ & 6,68 & 2,23 \\
\hline
\end{tabular}

Aesthetic quality of weld beads surface are higher for CCC and SOFT. The conventional short-circuiting bead was affected by spatter adherence on its edges, besides irregularities in the bead profile. Figure 17 
shows the superior view of the performed deposits.

One of the distinctive features of the current controlled (CC) short-circuiting MIG/MAG versions is their spatter minimizing capabilities. Therefore, this study comprised the development of a method of evaluating spatter generation. The percentage of spatter was calculated as describe in the Experimental Procedure from a $640 \times 156$ pixel image acquired over 5 seconds. An average spatter generation index of $0.2 \%$ was obtained for CCC and SOFT and, for the conventional short-circuiting process, $1.5 \%$, as can be seen in Fig. 18. This result converges with the stability evaluation based on stability indexes proposed by the literature as discussed above. Spatter generation is, to a great extent, related to higher arc reopening electric power. s.

In order to verify the transference of the bead-on-plate results to a real weld joint and assess the practical applicability of the processes, flat position joint filling tests were performed using a v-type. Joint configuration and welding electric parameters are the same as for the bead-on-plate experiments, and described in the Experimental Procedure. Mechanization parameters for each weld pass can be seen in Table 3.

Table 3

- Welding mechanization parameters.

\begin{tabular}{|lllll|}
\hline & Root & $\mathbf{1}$ & $\mathbf{2}$ & $\mathbf{3}$ \\
\hline Amplitude $(\mathrm{mm})$ & 3.3 & 4.5 & 5.8 & 7.2 \\
\hline Frequency $(\mathrm{Hz})$ & 0.6 & 0.5 & 0.7 & 0.9 \\
\hline Stop Time $(\mathrm{s})$ & 0.3 & 0.2 & 0.3 & 0.4 \\
\hline Welding Speed $(\mathrm{cm} / \mathrm{min})$ & 13 & 11.5 & 15 & 18.5 \\
\hline
\end{tabular}

SOFT was considered not suitable for root passes, yielding excessive penetration and tendency to burnthrough due to the intensity of the arc pressure on the weld pool. The root pass with the conventional short-circuiting MIG/MAG process and the CCC resulted in adequate penetration and good fusion of the edges. However, the conventional version presented higher detachment frequency variation, which affect the regularity of the average current and cause operational instabilities. Regarding the filling passes, lack of fusion was found for the conventional MIG/MAG and the CCC, reflex of inferior energetic contribution, in relation to the SOFT, which was unaffected by this discontinuity. The macrographs of these samples are in Fig. 19.CCC performed best for the root pass and SOFT, for the filling passes.

\section{Conclusion}

In a current scenario of profusion of launching and marketing of new versions of the MIG/MAG process, there is a concurrent rise of uncertainty and difficulty to understand their distinctive features and, even worse, to be able to correctly parameterize them and extract the best possible performance from them. This surely impairs industrial applicability, implementation and development of these process, which 
indeed have a lot to offer. The present paper deals with three different families of the short-circuiting MIG/MAG process, including two representatives of the new technologies, seeking to shed some light when considering investigation or application of this process.

Based on the results presented, it is possible to draw technological conclusions on the side of performance and comparison among three different MIG/MAG process modalities (representing three families of techniques), as well as conclusions regarding the phenomenology involved, as follows:

- The CCC Process presented the lowest arc restriking current and power values. This seems to have a great extent of influence over the arc pressure (plasma jet, gas expansion and metal vaporization), dimensions of the weld pool crater (or depression), and consequently, over HAZ dimensions (smaller). Despite having the smallest weld pool and weld pool crater, the CCC yields a bead with intermediary dimensions (between SOFT, largest, and conventional MIG/MAG, smallest). Lower power during arc time for the conventional MIG/MAG and higher power during arc time for SOFT account for this.

- The work, in Joules, carried out by SOFT in the arc phase was less than by the others, even presenting a similar average power, indicating greater energy efficiency of the process in relation to the others.

- Power during arc time is the parameter exerting most of the influence over heating of the workpiece. The SOFT process presented higher temperature values, due to the larger time of permanence of high power values during the arc time, which is the time where the weld pool and workpiece are being heated by the arc. This effect is supported by a large pool and crater of this process version, which in turn foster heat transfer from the pool to the workpiece. .

- Both CCC and SOFT showed lower spatter emission in relation to the conventional MIG/MAG. Technologies reducing the arc restriking power is effective in this sense;

- The image analysis method proved to be efficient to evaluate the spatter emission, with spatter adherence observed on the workpiece corresponding to higher spatter genetration index calculated by the method based on image processing.

- Although the results of bead geometry present similarity in bead-on-plate deposition, result in groove joints (different conditions of heat transfer and arc/bead/piece interface) demonstrated the performance difference in a real union application situation. That is, the analysis of deposition on plate as an indication of welding process performance characterization is limited. Further similar analysis methodologies hall take place for joint beads, coating applications and additive manufacturing.

- CCC is a very interesting process for root pass application, especially large gaps. Due to its low heat input, it is not a process indicated to filling passes, because it presents susceptibility to lack of fusion. SOFT is more advisable for filling passes.

\section{Declarations}


Acknowledgements The research proposed in this paper was supported by Labsolda - Mechatronic and Welding Institute and Federal University of Santa Catarina.

Author contribution Régis Henrique Gonçalves e Silva contributed to the paper structure, methodology and did the final proofreading; Daniel Galeazzi conducted the experimental procedures and was responsible for writing the paper; Pedro Correa Jaeger Rocha assisted the experimental procedures and proofreading, Alberto Bonamigo Viviani provided literature, methods and experimental support; Rafael Albino Bernardi provided literature and was co-responsible for writing the paper.

Availability of data and material The raw and processed data required to reproduce these findings cannot be shared at this time as the data also forms part of an ongoing study.

\section{Declarations}

Ethics approval Not applicable.

Consent to participate All authors have approved to participate.

Consent to publication The manuscript is approved by all authors for publication.

Conflict of interest The authors declare that they have no conflict of interest.

\section{References}

[1] Moyer N, (2002) The Evolution of Shielding Gas. Welding Journal 81: 51-52,

[2] Scotti A, Ponomarev V, Lucas W (2012) A scientific application oriented classification for metal transfer modes in GMA welding. Journal of Materials Processing Technology 212:1406 - 1413. DOI:10.1016/j.jmatprotec.2012.01.021

[3] Wong Y R, Ling S (2014). An investigation of dynamical metal transfer in GMAW-Effects of argon shielding gas. Journal of Materials Processing Technology 214:106-111.

Doi:10.1016/j.jmatprotec.2013.08.003

[4] Zeng M, Huang J, Zhang Y, Hu P (2017). Modeling for GMAW process with a current waveform control method. Journal of Materials Processing Technology 240:404-413.

Doi: 10.1016/j.jmatprotec.2016.10.018

[5] Kah P, Suoranta R, Martikainen J (2013) Advanced gas metal arc welding processes. International Journal of Advanced Manufaturing Technology 67:655-674. DOI:10.1007/s00170-012-4513-5

[6] Mvola B, Kah P, Layus P (2018) Review of current waveform control effects on weld geometry in gas metal arc welding process. The International Journal of Advanced Manufacturing Technology 96:4243 - 
[7] Scotti A, Meneses V, A (2014) Governing parameters affecting fume generation in short-circuit MAG welding. Weld World 58:367-376. DOI 10.1007/s40194-014-0122-2

[8] Dutra J C, Silva R H G (2009) MIG/MAG - short-circuit metal transfer - control of the current wave form - fundamentals of the CCC and STT systems. Welding International 23:181-185. DOI:

$10.1080 / 09507110802543427$

[9] Buki A, Gorenshtein I M (1967) The stability and self adjustment of metal deposition with short-circuit of arc gap. Automation Welding.

[10] Shinoda T, Kaneda H, Takeuchi Y (1989) An evaluation of short-circuiting phenomena in GMA Welding. Welding ad metal fabrication.

[11] Kuszelyko R (1979) An objective solution of the welding process stability evaluation. IIW Document XII-F208-79.

[12] Yang D, Li H, Liu S, Song C, Yang Y, Shen S, Lu J, Liu Z, Zhu Y (2020) In situ capture of spatter signature of SLM process using maximum entropy double threshold image processing method based on genetic algorithm. Optics and Laser Technology 131 106371. DOI: 10.1016/j.optlastec.2020.106371.

[13] Schweier M, Haubold M W, Zaeh M F (2016) Analysis of spatters in laser welding with beam oscillation: A machine vision approach. CIRP Journal of Manufacturing Science and Technology 14:3542. DOI: 10.1016/j.cirpj.2016.05.004

[14] Horvat J, Prezelj J, Polajnar I, Čudina M (2011) Monitoring Gas Metal Arc Welding Process by Using Audible Sound Signal. Journal of Mechanical Engineering 57(3): 267-278. DOI:10.5545/sv-jme.2010.181

[15] Cayo E H, Absi S C (2008) Welding quality measurement based on acoustic sensing. ABCM Symposium Series in Mechatronics (3):571-579.

\section{Figures}




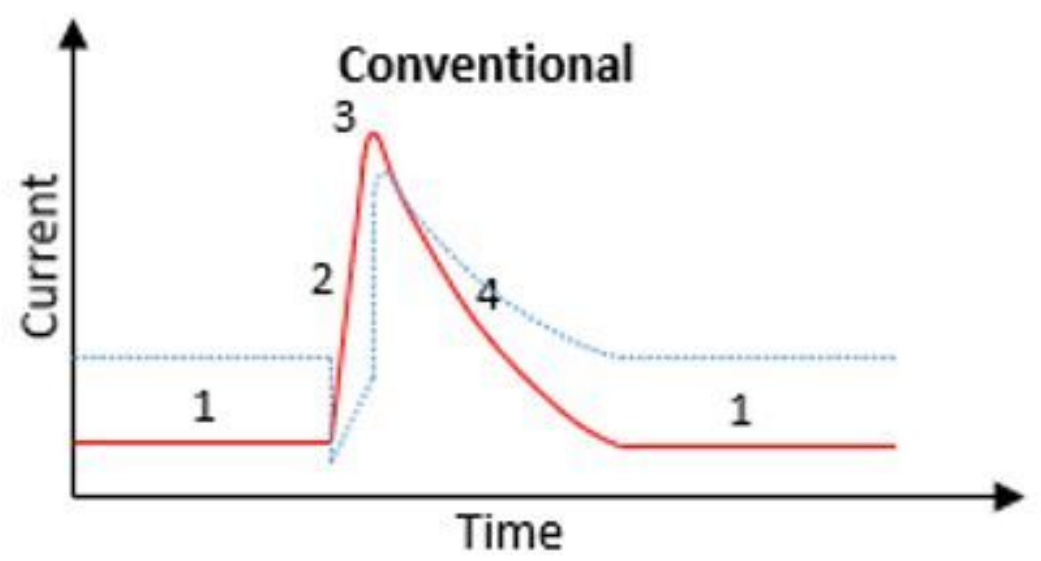

\section{Figure 1}

Typical waveform of MIG/MAG short-circuit process, where: 1) Base current as a function of reference voltage; 2) Current increase in short-circuit phase; 3) Droplet transfer in high current; 4) Current decrease for reference voltage adjusted.
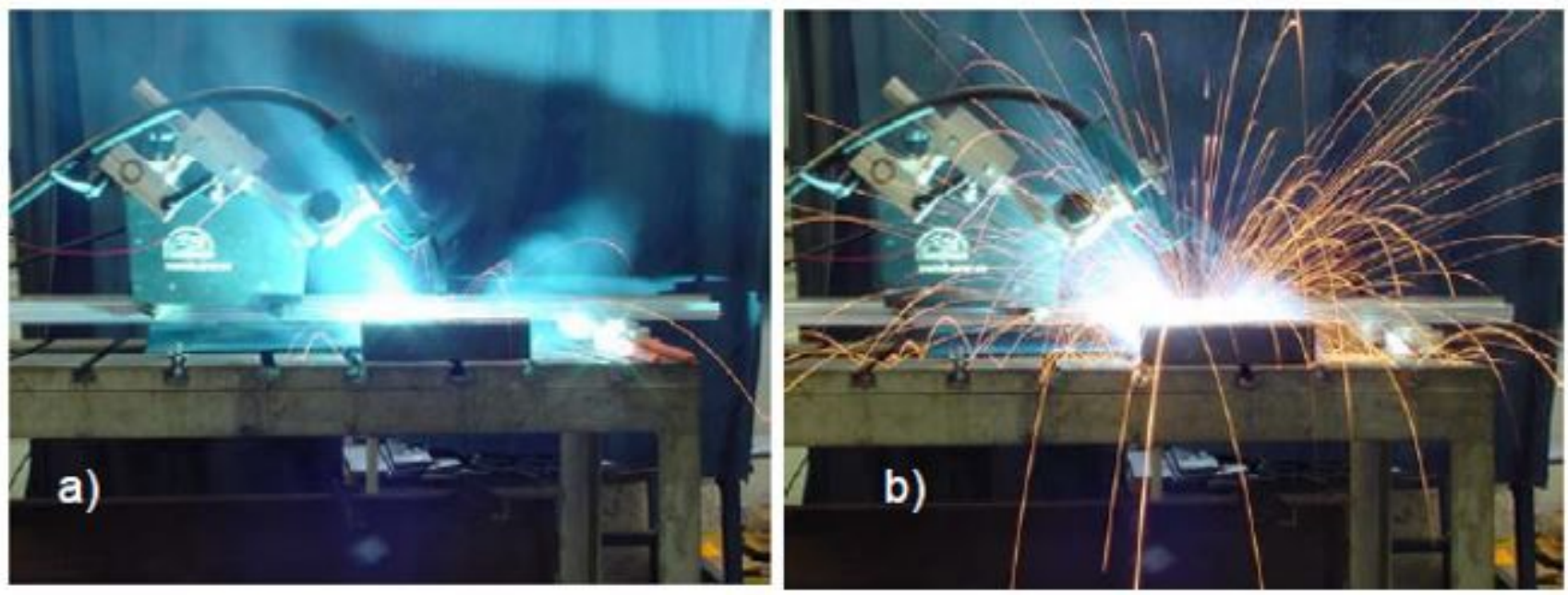

\section{Figure 2}

Qualitative spatter intensity assessment in a (a) Welding procedure with the CCC system and (b) a welding procedure with a conventional MIG/MAG process [8]. 


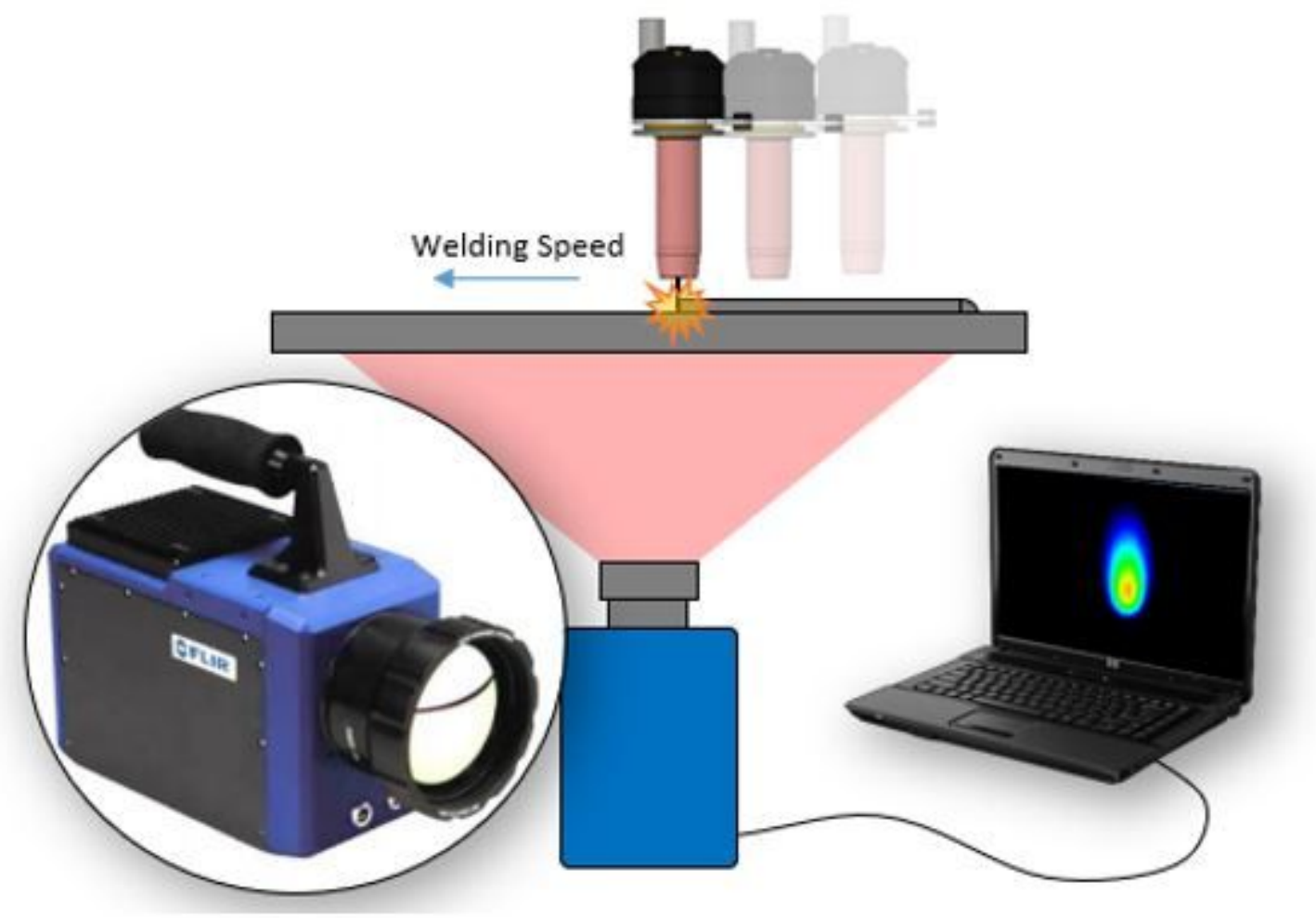

Figure 3

Schematics of equipment layout, plate, camera, torch and acquisition computer program. 
Cross section ( $\mathrm{mm}$ )

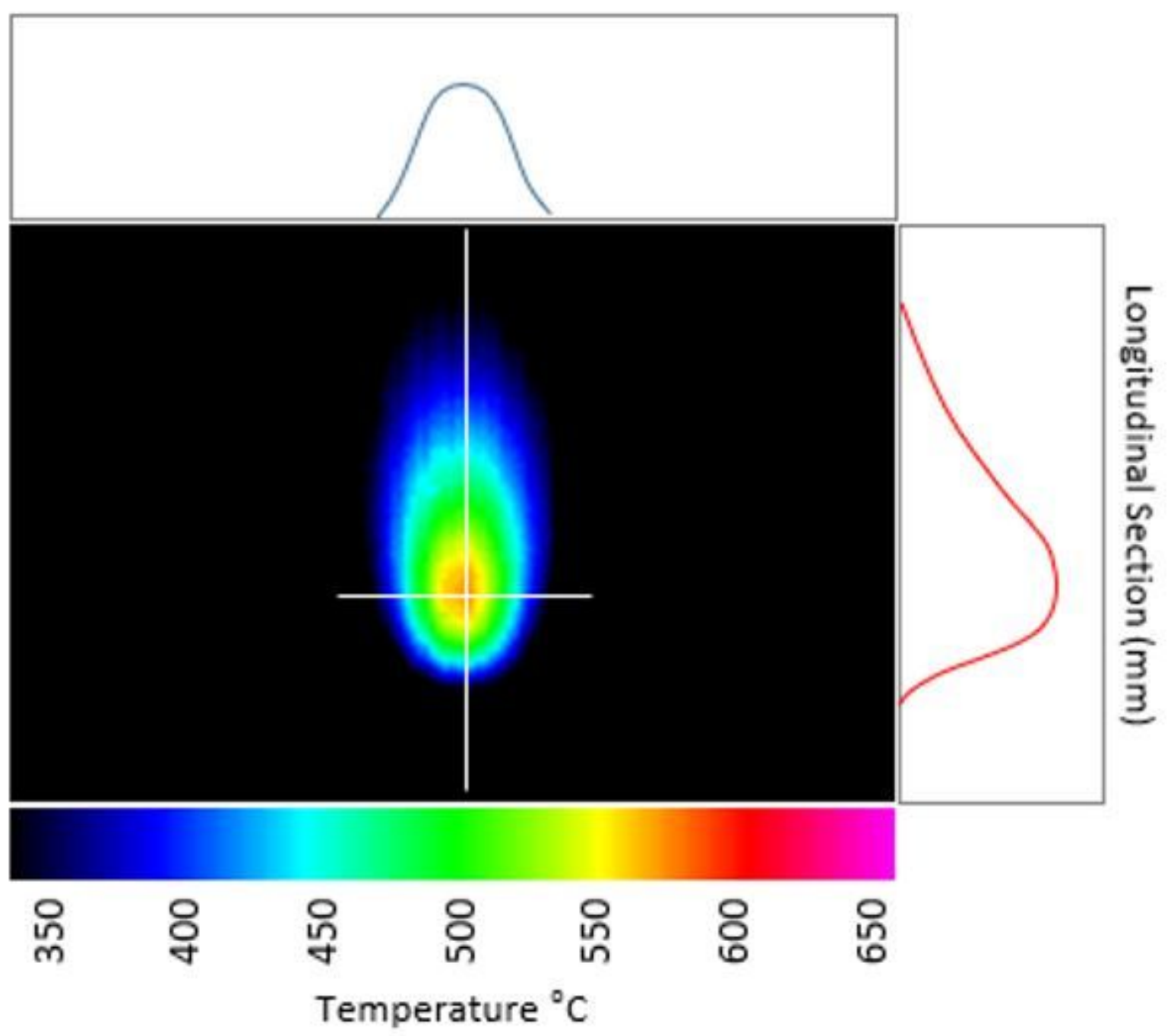

Figure 4

Schematic temperature measurement 


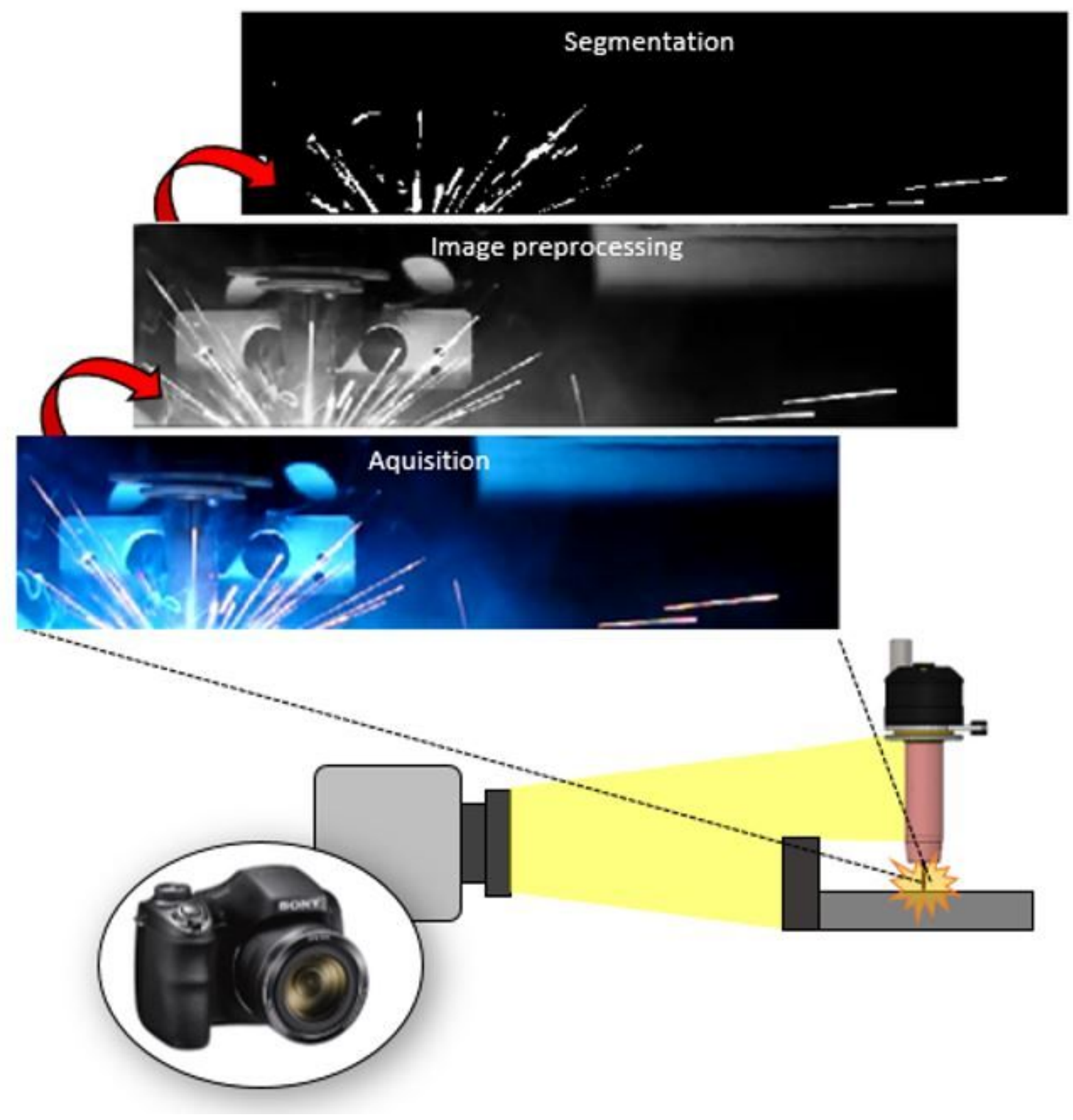

Figure 5

Schematic of the method of acquisition and treatment of frames for percentage counting of spatters. 

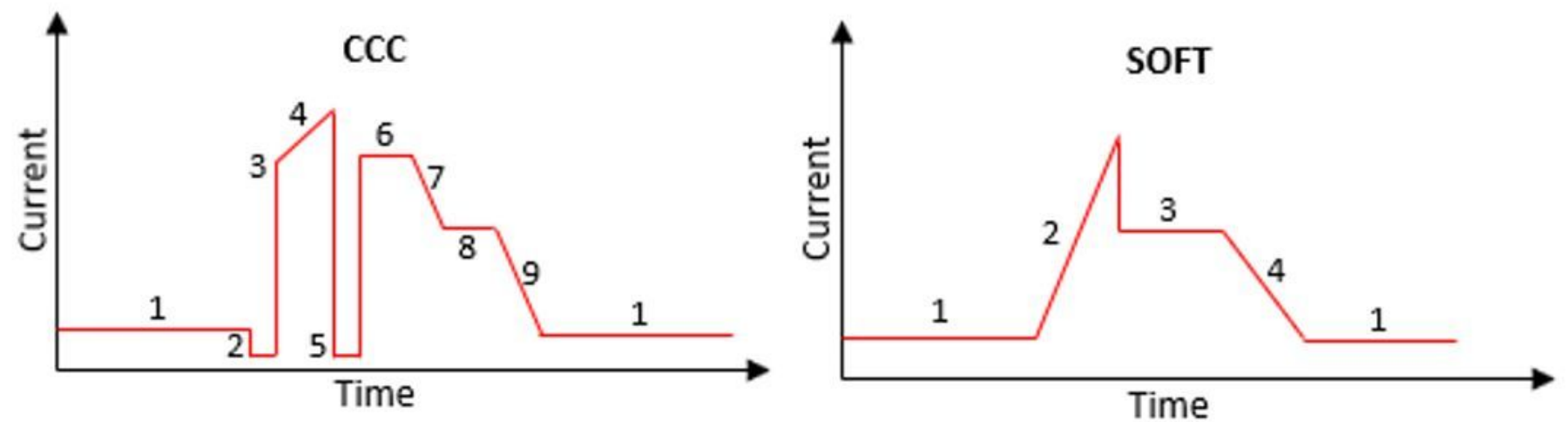

Figure 6

Typical current waveform of MIG/MAG current control variants. 


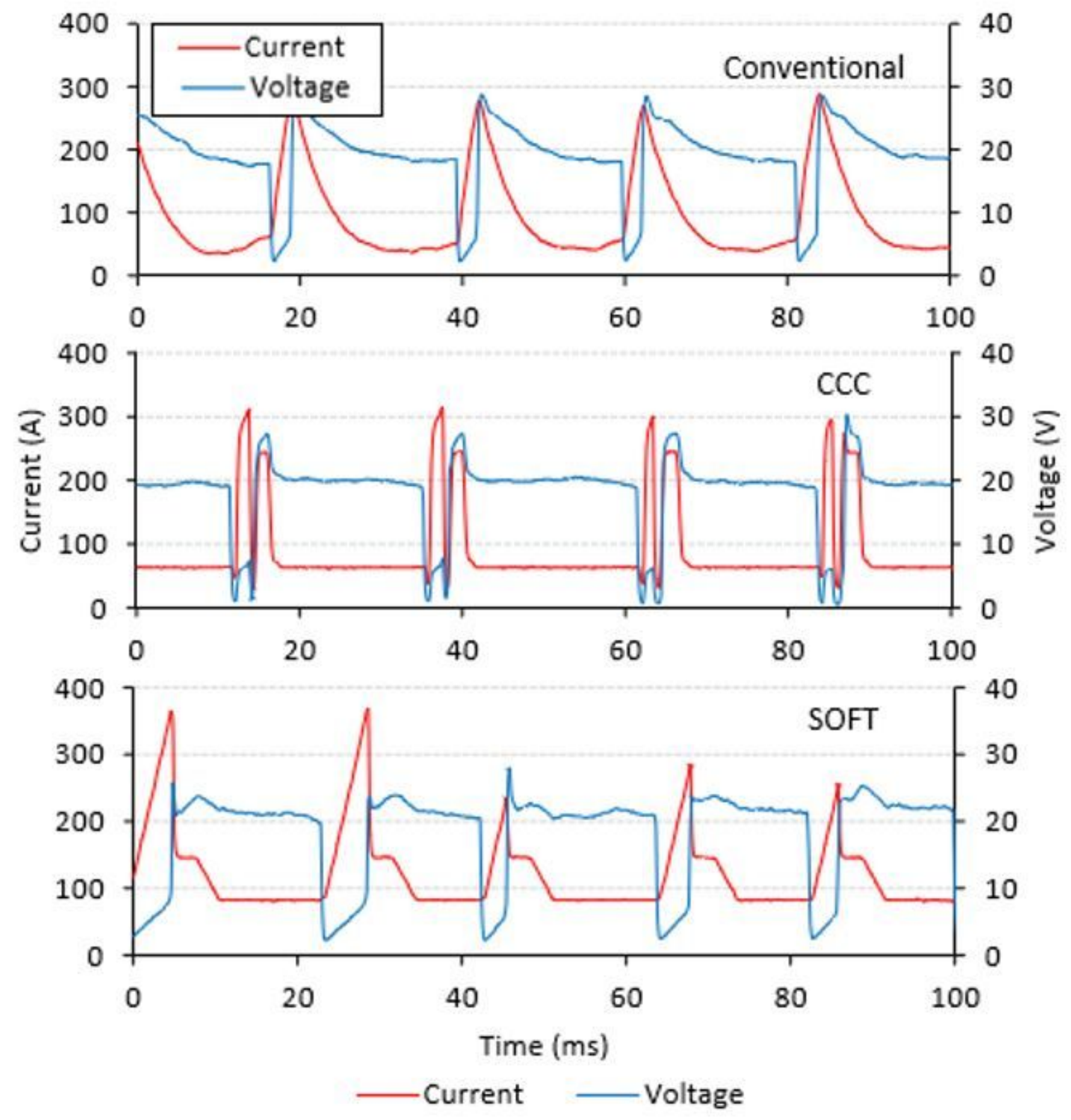

Figure 7

Current and voltage oscillogram of the conventional short-circuiting process, CCC and SOFT variants. 

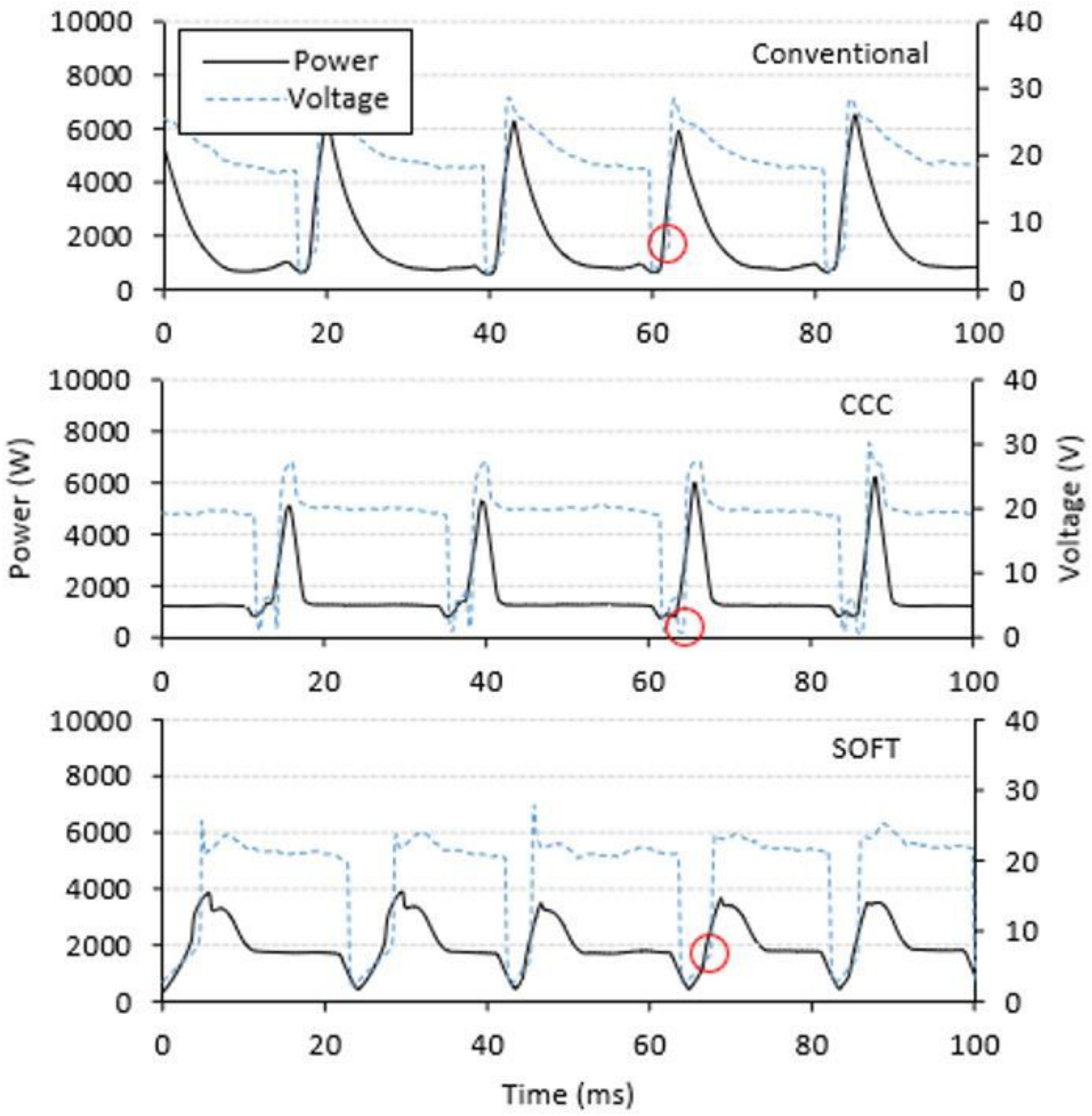

- Power -...-...Voltage

Figure 8

Power and voltage oscillogram of the conventional short-circuiting process, CCC and SOFT variants. Detailing the detachment point 

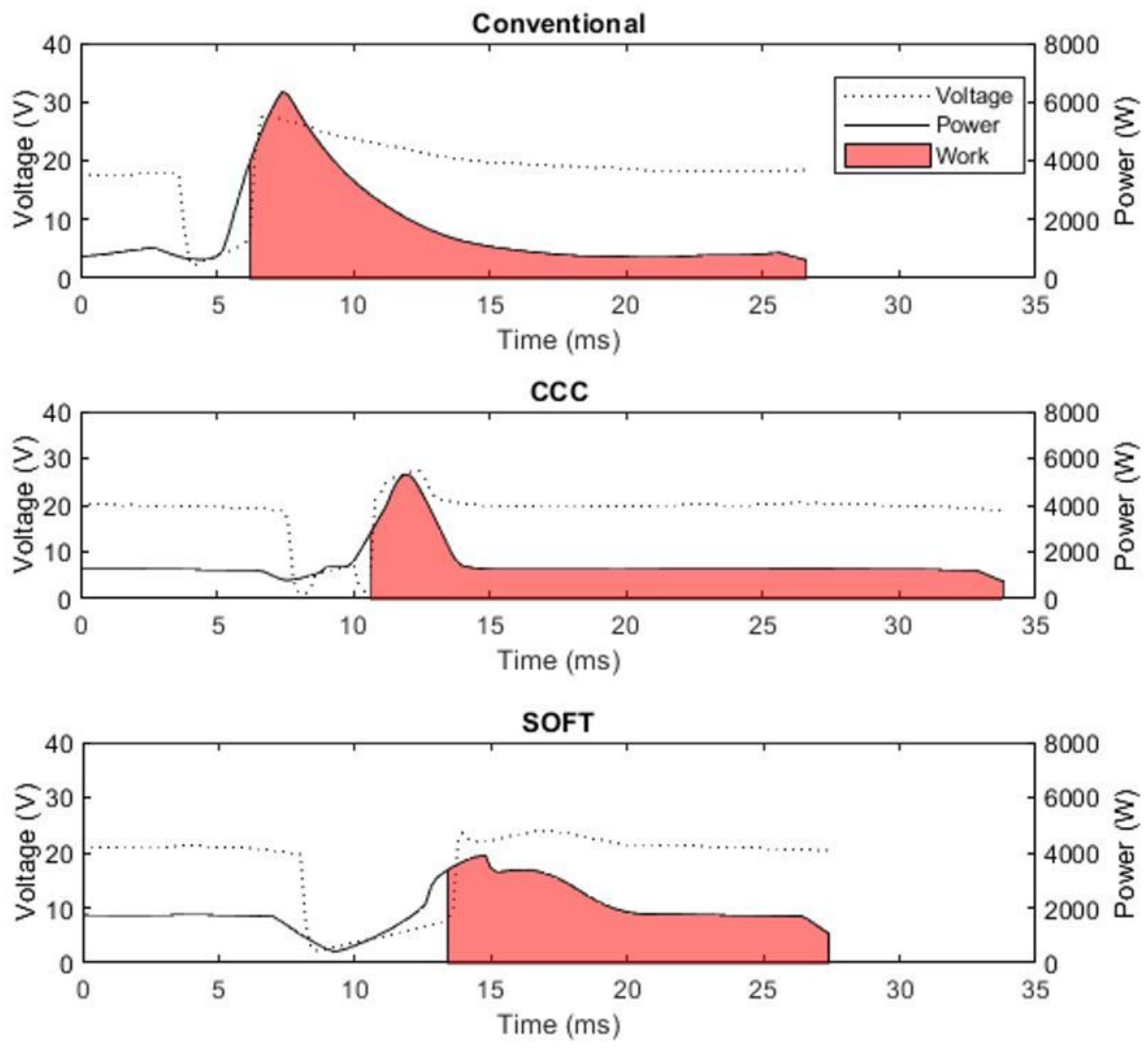

Figure 9

Work performed during the arc phase. 

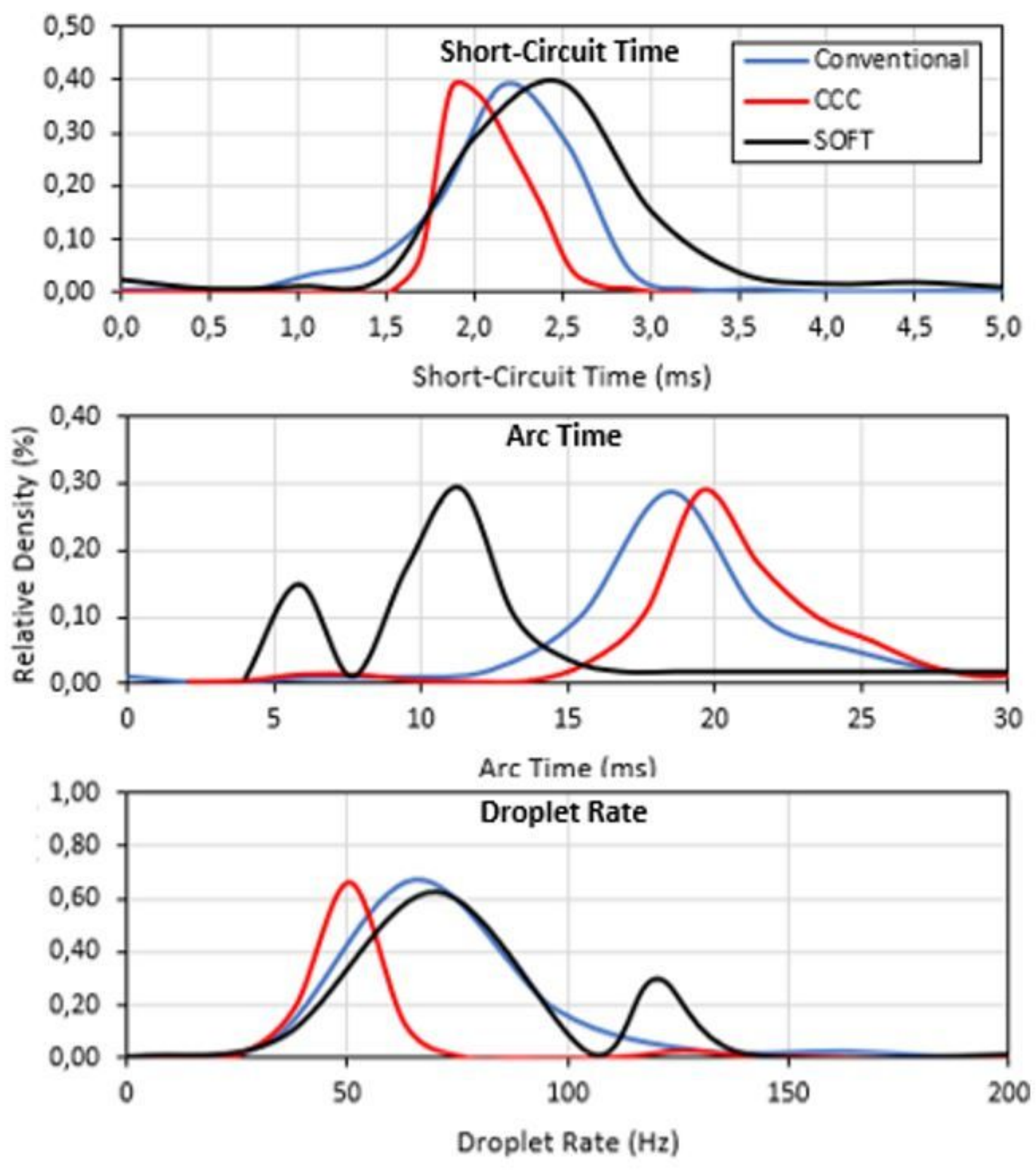

Figure 10

Arc time, short-circuit time and droplet detachment frequency (waveform frequency) histograms. 

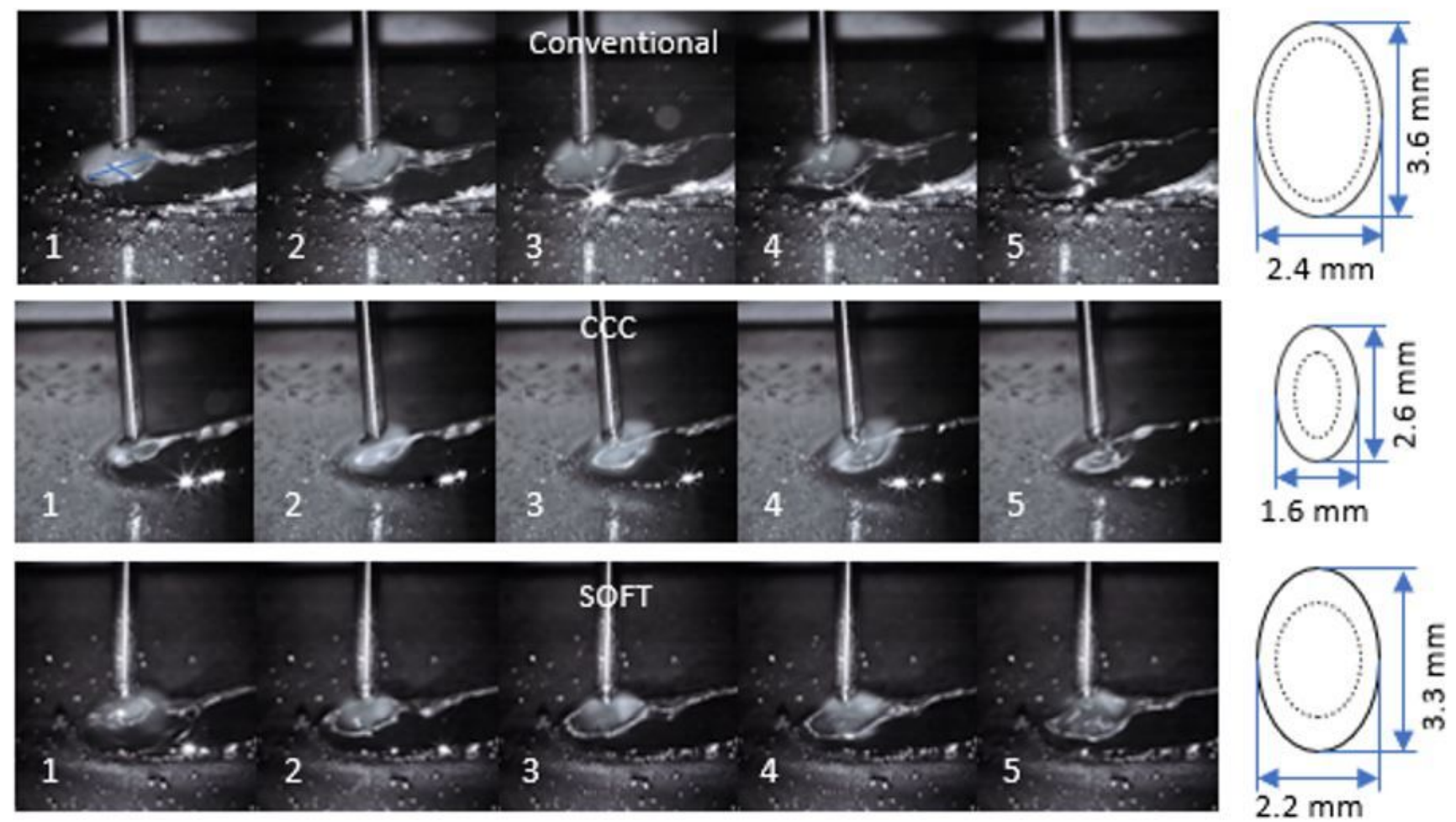

Figure 11

High-speed filming to evaluate the weld pool dynamic effects. 


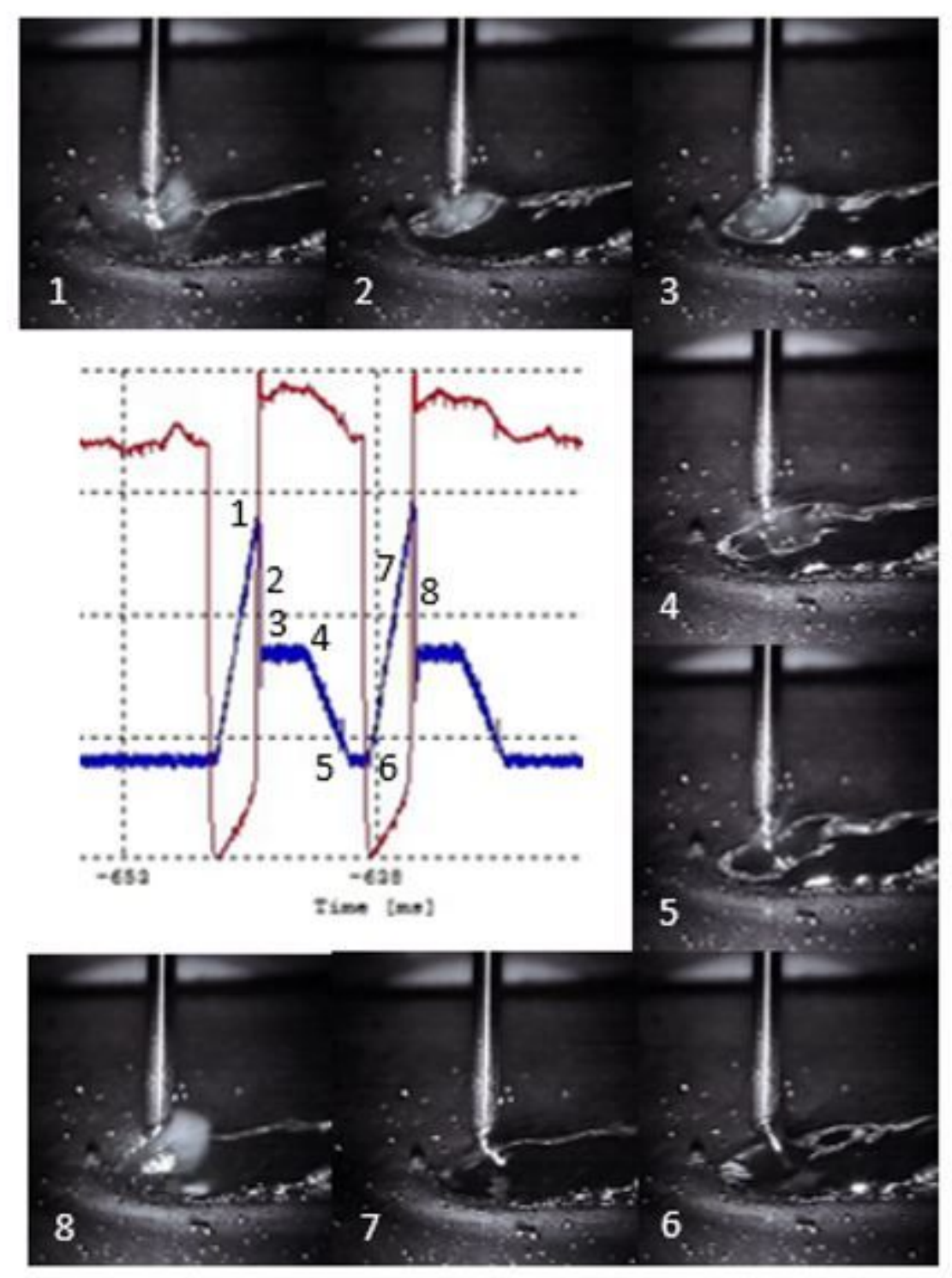

Figure 12

High-speed videography frames of the effect of the SOFT process on the weld pool oscillation. 

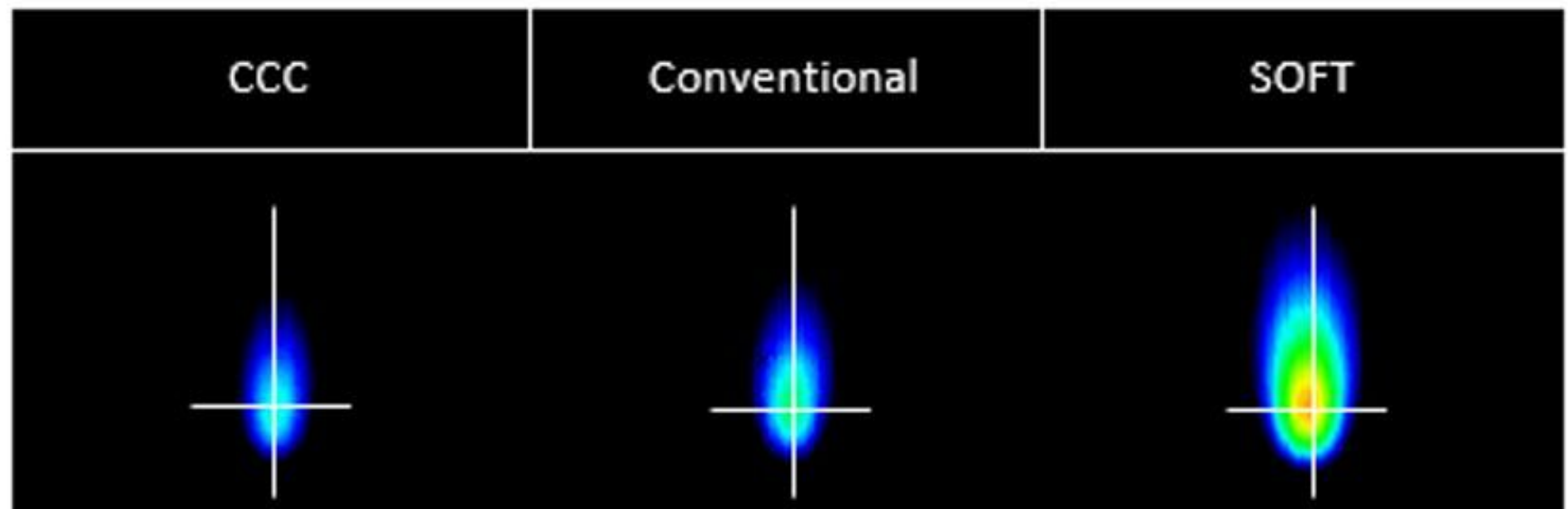

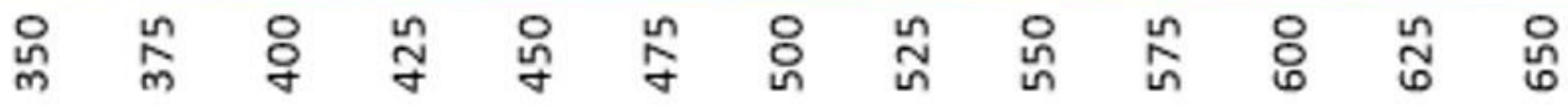 \\ Temperature ${ }^{\circ} \mathrm{C}$}

Figure 13

Thermograms of the workpieces' central region.

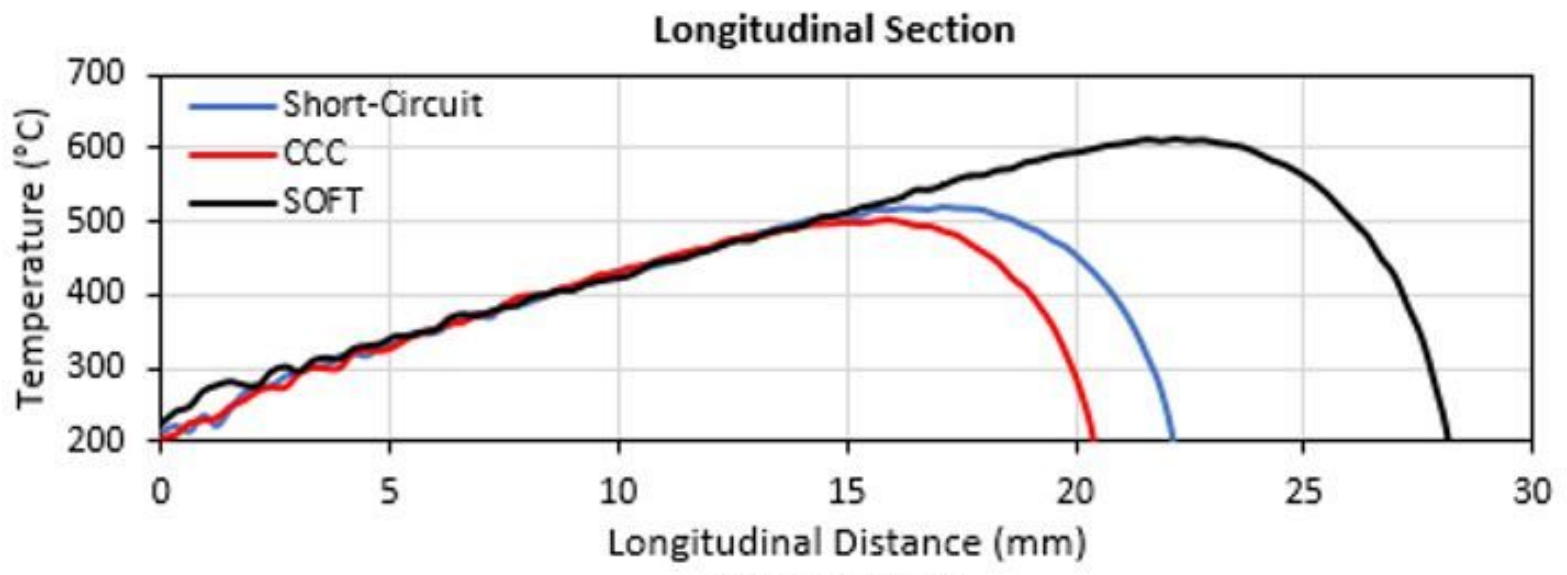

Cross Section

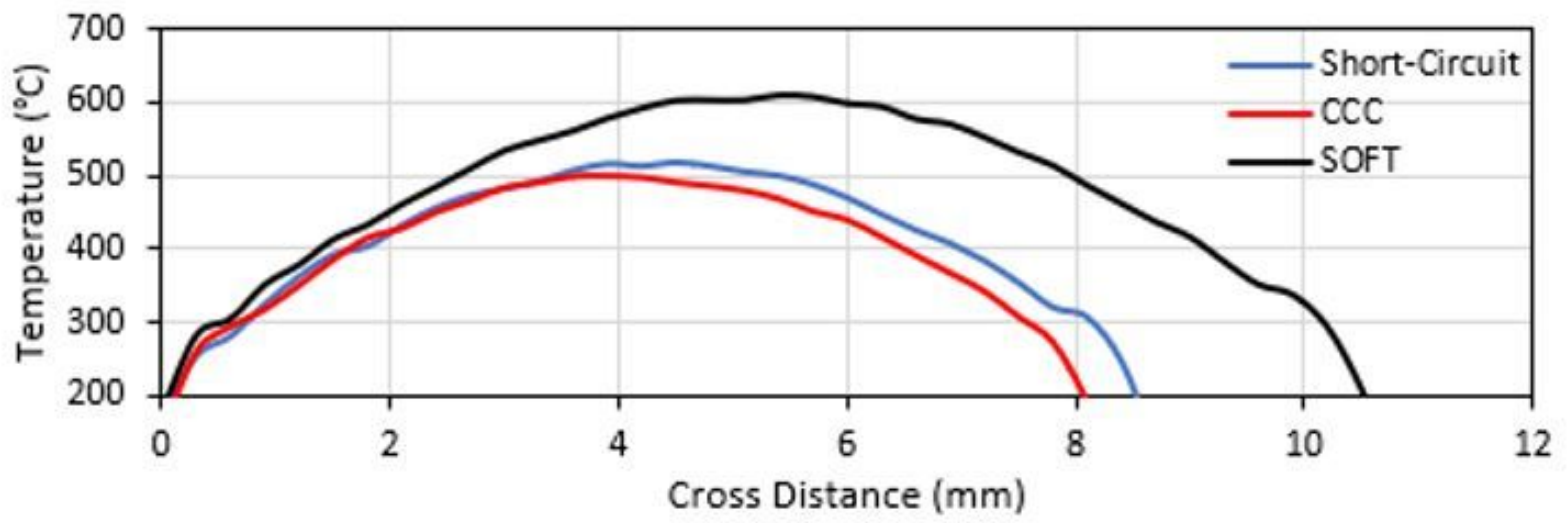


Figure 14

Thermal profile of the longitudinal and transversal section of the frame that represents the weld bead center.

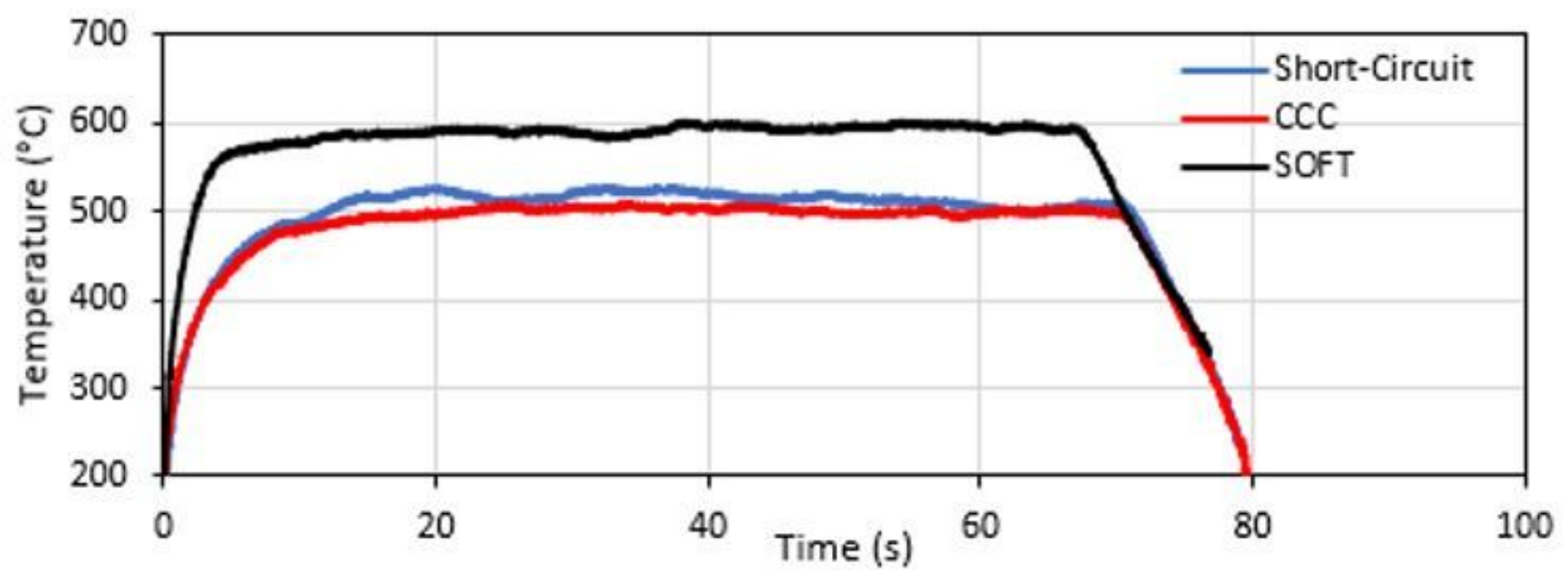

Figure 15

Thermal profile over time of the deposits performed with the three MIG/MAG process variants compared.

Conventional

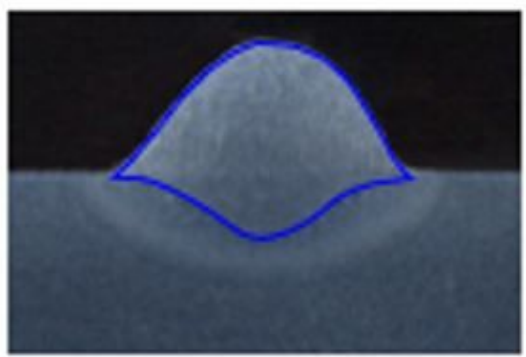

$\mathrm{CCC}$

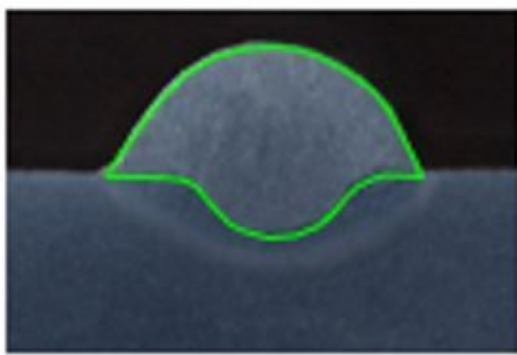

SOFT

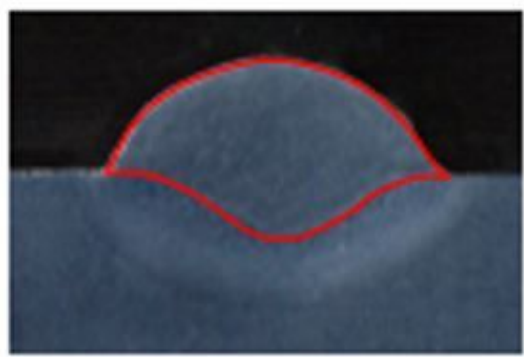

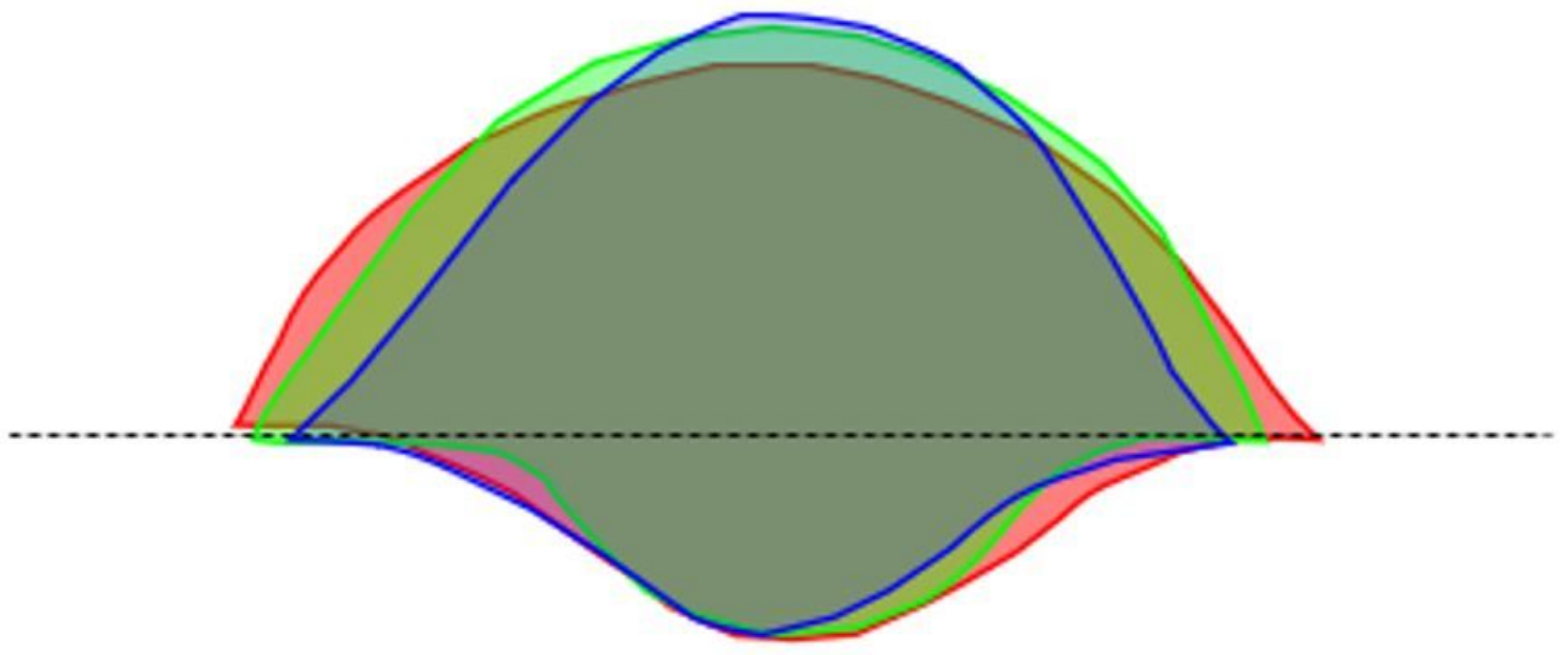

Figure 16 
Macrographs extracted from the center of the weld bead.
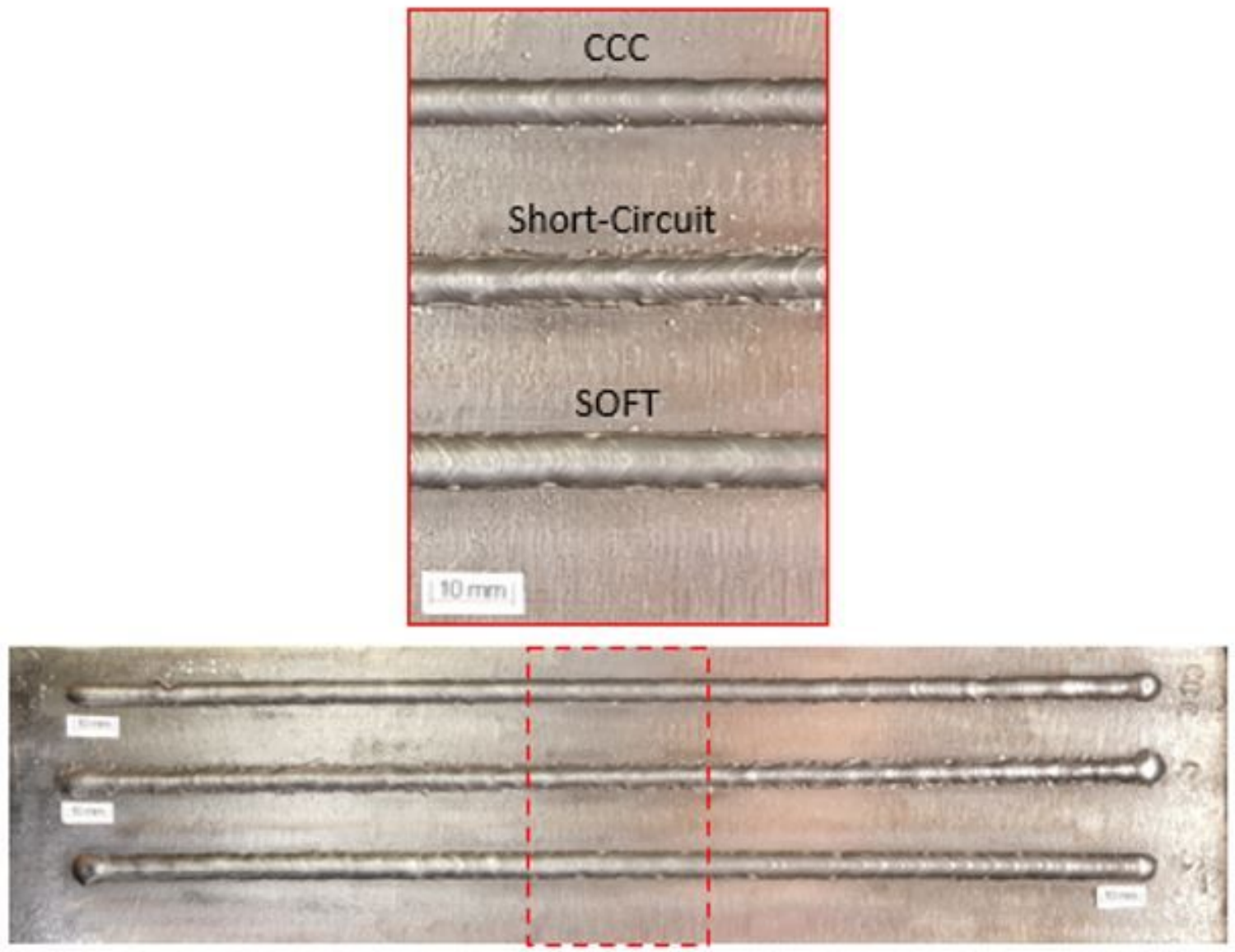

Figure 17

Surface appearance of the weld beads. 


\section{Short-Circuit}
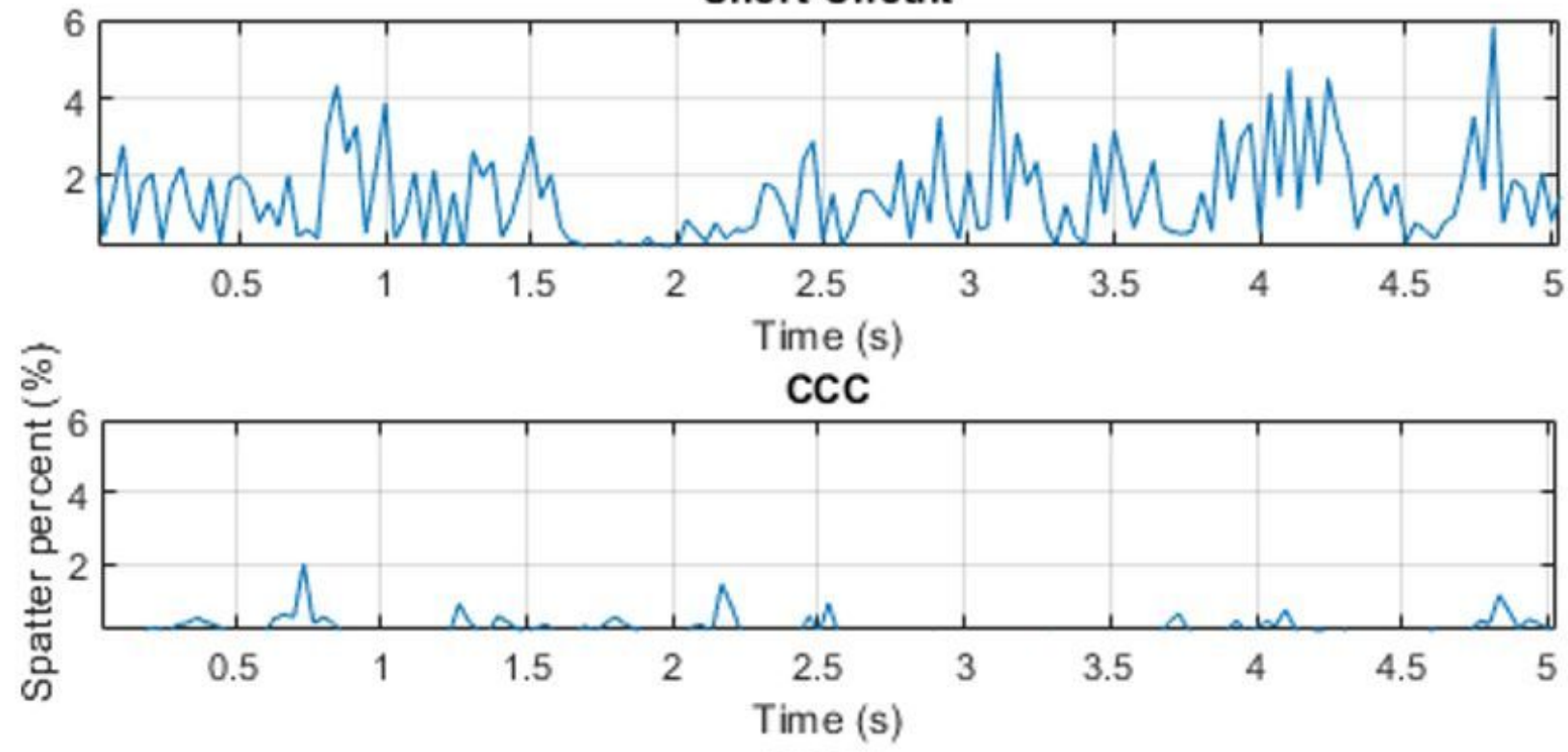

SOFT

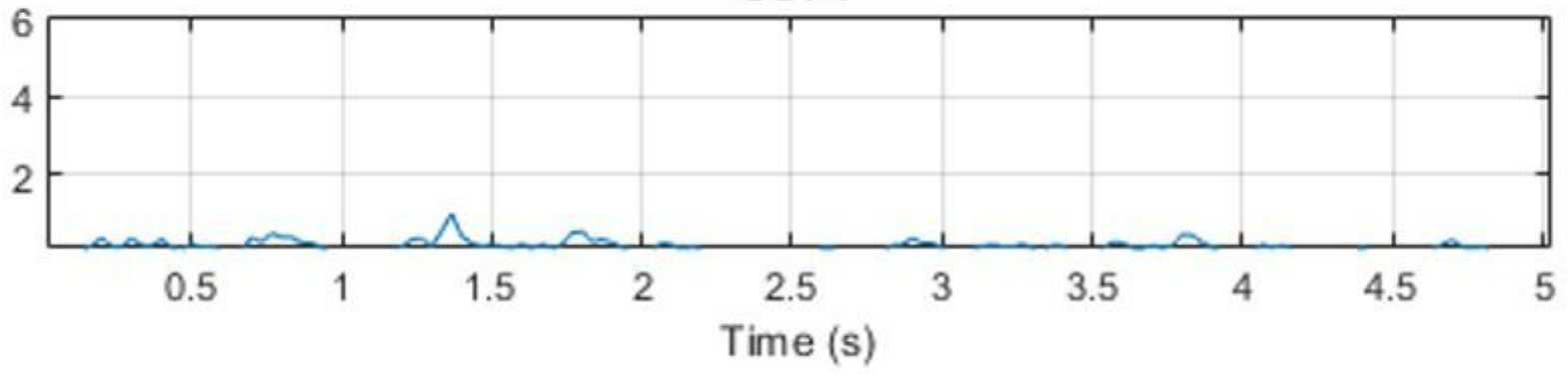

Figure 18

Spatter generation evaluation by application of a percentage index based on image processing.
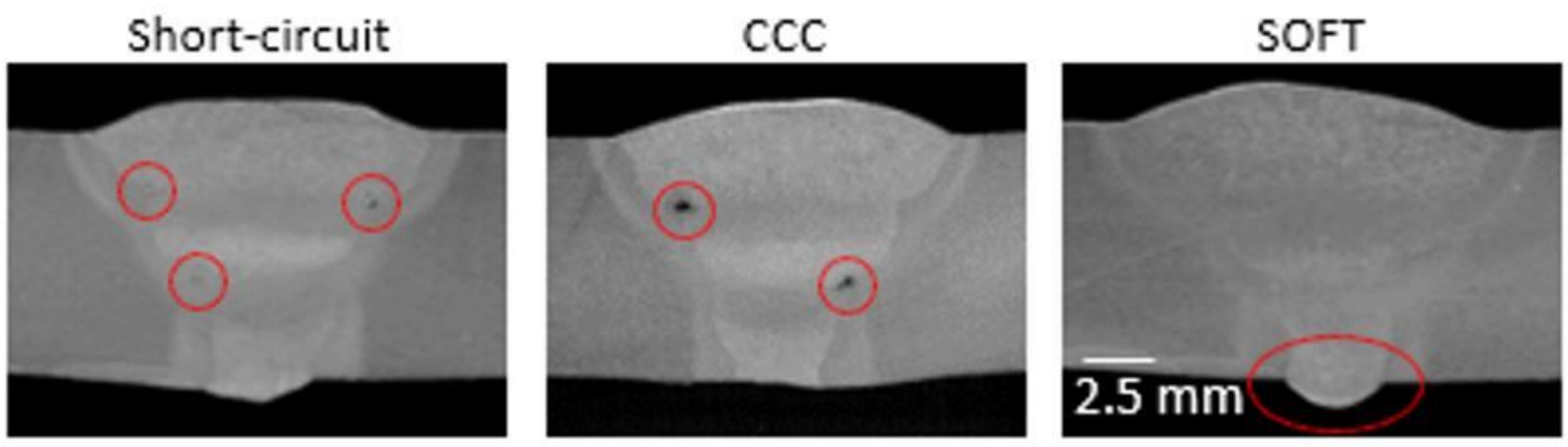

Figure 19

V-Groove test macrographs (lack of fusion highlited for the conventional MIG/MAG and CCC; tendency for excessive penetration highlighted for SOFT). 